\title{
COMPARING MR SPECTROSCOPY WITH COGNITIVE FUSION PROSTATIC BIOPSY IN THE DIAGNOSIS OF CARCINOMA PROSTATE- A PROSPECTIVE DESCRIPTIVE ANALYTIC STUDY
}

\author{
Periasamy Ponnusamy1, Senthilvel Arumugam², Udayakumar Madesh ${ }^{3}$
}

1Professor, Department of Urology, Government Kilpauk Medical College and Hospital, Kilpauk, Chennai, Tamilnadu.

2Professor, Department of Urology, Government Kilpauk Medical College and Hospital, Kilpauk, Chennai, Tamilnadu.

${ }_{3}^{3}$ MCh Postgraduate Student, Department of Urology, Government Kilpauk Medical College and Hospital, Kilpauk, Chennai, Tamilnadu.

\section{ABSTRACT}

\section{BACKGROUND}

The current diagnostic approach for prostate cancer- PSA and digital rectal examination followed by transrectal ultrasound biopsies lack both sensitivity and specificity and offer only limited information about the aggressiveness and stage. Recent scientific work supports the rapidly growing use of multiparametric magnetic resonance imaging (MP-MRI) as the most sensitive and specific imaging tool for detection, lesion characterisation and staging of prostate cancer. Its use may improve many aspects of prostate cancer management from initial detection of significant tumours using MP-MRI-guided biopsies for evaluation of biological aggressiveness and accurate staging which can facilitate appropriate treatment selection.

Aims and Objectives- To study the relationship between MR spectroscopy and prostate fusion biopsy in carcinoma prostate.

\section{MATERIALS AND METHODS}

The study was conducted on 30 patients, who attended Kilpauk Medical College Outpatient Department from August 2016 to January 2018, with an abnormal DRE and/ or PSA $>4 \mathrm{ng} / \mathrm{mL}$. All these patients were subjected to MP-MRI 1.5 Tesla with endorectal coil imaging, sextant core and lesion targeted prostatic biopsy. MRSI findings (choline - citrate ratio $>2.5$ is considered positive) and biopsy results were analysed and correlated.

\section{RESULTS}

Out of these 30 patients, biopsy revealed malignancy in 22, of which 16 had elevated choline - citrate ratio $>2.5$. Gleason grade was $>7$ in 10 cases, 7 in 6 cases and $<7$ in 6 cases. Choline - citrate ratio was elevated in all cases (100\%) of high-grade tumour (Gleason grade $>7$ ), 4 out of 6 cases (66\%) with Gleason score of 7 and in 2 (33\%) of 6 cases with Gleason score of $<7$. Cholinecitrate elevated in 2 patient's biopsy shows chronic prostatitis.

\section{CONCLUSION}

MR spectroscopy of prostate is useful in diagnosing clinically significant and high-grade cancers. Sensitivity was low for low-grade tumours. It is ideally used as an adjunct with other functional studies rather than for primary diagnosis.

\section{KEYWORDS}

MRI Spectroscopy, Cancer Prostate, Prostate Biopsy.

HOW TO CITE THIS ARTICLE: Ponnusamy P, Arumugam S, Madesh U. Comparing MR spectroscopy with cognitive fusion prostatic biopsy in the diagnosis of carcinoma prostate- a prospective descriptive analytic study. J. Evolution Med. Dent. Sci. 2018;7(18): 2172-2176, DOI: $10.14260 /$ jemds/2018/488

\section{BACKGROUND}

Prostate cancer most often occurs in the outer glands, in which the tumour can be detected via a digital rectal examination (DRE). Nevertheless, approximately $23 \%$ to $45 \%$ of carcinomas still remain undetected by this method. $15 \%$ to $20 \%$ of the prostate cancers are located in the transitional zone and are thereby difficult to access by palpation.(1)

The PSA level (prostate specific antigen) introduces another possibility for early detection of prostate carcinoma. It should be noted that an inflammation of the prostate gland (prostatitis) or a benign enlargement of the prostate gland (nodular hyperplasia) can also increase the PSA levels.

\section{'Financial or Other Competing Interest': None.}

Submission 04-04-2018, Peer Review 16-04-2018,

Acceptance 18-04-2018, Published 30-04-2018.

Corresponding Author:

Dr. Periasamy Ponnusamy,

Department of Urology, $5^{\text {th }}$ Floor, Surgical Block,

Government Kilpauk Medical College and Hospital,

Kilpauk-600010, Chennai, Tamilnadu.

E-mail: drppsamysubha@gmail.com

DOI: $10.14260 /$ jemds $/ 2018 / 488$

\section{(c) $(1) \risingdotseq$}

Moreover, prostatic carcinoma was also present in $25 \%$ of patients with a PSA level below the critical $4 \mathrm{ng} / \mathrm{mL}$ threshold. In order to facilitate a more comprehensive early detection of the carcinoma, additional diagnostic imaging methods should be utilised.(1)

Transrectal ultrasound (TRUS) can be considered another method to confirm the existence of a suspected tumour. An ultrasound steered sextant biopsy could also be advised. This method offers a sensitivity of $17 \%$ to $53 \%$ and a specificity of $40 \%$ to $63 \%$ depending on the study. Of the patients who underwent a sextant biopsy, $64 \%$ to $78 \%$ experienced minimal side-effects such as urinary tract infections, gross haematuria and haemospermia.(1)

Magnetic resonance imaging (MRI) of the prostate in combination with a dedicated endorectal coil is a valid method for the visualisation of the prostate and its associated neoplasm. The coil can be positioned close to the target tissue and thereby produce highly detailed images of the target and surrounding area, thus allowing for an accurate interpretation. Suspected tumour areas in the peripheral zones are typically characterised by low signal, while these are often not easily visualised in the central gland due to preexisting benign prostate hyperplasia that presents as mostly 
in homogeneous.(2) Moreover, in many patients receiving hormone treatments, the prostate gland experiences a signal loss, therefore making it very difficult to distinguish a suspected tumour area from that of a healthy area.(3) Magnetic resonance spectroscopy of the prostate is a method that can be combined with standard imaging in order to minimise or reduce these factors.(2)

\section{Objective}

To study the relationship between MR spectroscopy and prostate fusion biopsy in carcinoma prostate.

\section{MATERIALS AND METHODS}

\section{Patient Recruitment}

A prospective, descriptive, analytic study was done in our institute from August 2016 to January 2018 after board approval. Patients with suspicious of carcinoma prostate attending our outpatient department were included in the study, patients who were having contraindications to undergo MRI were excluded from the study.

\section{Imaging Protocol}

All imaging studies were performed using a $1.5 \mathrm{~T}$ MRI scanner and a body coil for transmission and a four-coil phased-array torso coil for reception. The MRI protocol conformed to the European Society of Urogenital Radiology (ESUR) guidelines. Axial T1-weighted spin-echo MR images were obtained for detecting intraglandular haemorrhage. Subsequent T2-weighted fast spin-echo MR images were obtained in the axial, sagittal and coronal planes of the prostate and seminal vesicles for identifying the prostate zonal anatomy, three-dimensional (3D) diameter of the transitional zone and pathology. Axial diffusion-weighted imaging and MRI spectroscopy were subsequently performed, and the corresponding apparent diffusioncoefficient maps were generated.

\section{Cognitive MRI-TRUS Fusion Biopsy}

Patients with suspicious lesions following MP-MRI received a subsequent target biopsy. TRUS-guided biopsy was performed. The patient was placed in the left lateral decubitus position with bent knee. After sterilisation, cognitive MR-targeted biopsy was performed under TRUSguidance in axial scan. Cognitive registration of the suspicious area was localised through both gray scale and colour Doppler images. The lesion was identified on the basis of the zonal anatomy described or imaging landmarks including bladder neck, cyst or hyperplastic nodules. A needle adapter was attached to the ultrasound transducer for placing the biopsy needle. An 18-gauge/ 20 -cm spring-loaded biopsy needle was used for biopsy. Lesion targeting, and tissue acquisition were performed under continuous real-time ultrasound monitoring. Two needle passes were performed for each target lesion.

Inclusion Criteria- All patients with elevated PSA levels ( $>4$ $\mathrm{ng} / \mathrm{mL}$ ) and/ or abnormal DRE attending urology clinic of our institution.

Exclusion Criteria- Patients with pacemaker implantation or other contraindications for MRI examinations were excluded and informed consent was obtained from all patients.

\section{Statistical Methods}

The correlation between prostatic biopsy and MR spectroscopy results were reported as sensitivity and specificity. The data was analysed using SSPP version 16 and Microsoft Excel 2007. Descriptive statistics was done for all data and were reported as in term of mean value percentage, sensitivity, specificity, positive predictive value and negative predictive value.

\section{RESULTS}

Thirty patients were included in this study with a mean age of 70 years (58 to 83 years).

\section{MRI Spectroscopy}

The MRSI scan analysis was done. The lesions with elevated choline - citrate ratio was also marked. The cancer-detection rate was $78 \%(16 / 22)$. Average choline - citrate ratio in patients with malignancy was $2.70 \pm 0.2$, whereas patients with negative biopsy choline was citrate ratio as $0.35 \pm 0.10$.

\begin{tabular}{|c|c|}
\hline No. of Patients & 30 \\
\hline Age & $58-83$ (mean- 70) \\
\hline PSA Levels & $4-72 \mathrm{ng} / \mathrm{mL}($ mean- 28$)$ \\
\hline USG Gland Volume & $30 \mathrm{cc}-70 \mathrm{cc}$ (mean- 45 cc) \\
\hline Abnormal DRE & 18 pts. \\
\hline Elevated PSA > 4 ng/ dL & 30 pts. \\
\hline \multicolumn{2}{|c|}{ Table 1 } \\
\hline
\end{tabular}

\section{Pathology}

Of the 22 cancer patients, six, six and ten patients showed Gleason scores of $3+3,3+4$ or $4+3$, and $4+4$ respectively (Table 2). All of the prostate cancers detected in this study were clinically significant. Eight of the 22 cancer patients received a prostatectomy. The Gleason's score of the final pathology was concordant with the biopsy results in six patients, upgraded in two patients.

\begin{tabular}{|c|c|}
\hline Positive for Malignancy & $\mathbf{2 2}$ \\
\hline Choline/ citrate $->2.5$ & $16(78 \%)$ \\
\hline Choline/ citrate $-<2.5$ & $6(22 \%)$ \\
\hline \multicolumn{2}{|c|}{ Table 2} \\
\hline
\end{tabular}

\begin{tabular}{|c|c|c|}
\hline Positive for Malignancy & $\mathbf{2 2}$ & $\begin{array}{c}\text { Choline Citrate } \\
\text { Ratio > 2.5 }\end{array}$ \\
\hline Gleason's grade $>7$ & 10 & $10(100 \%)$ \\
\hline Gleason's grade -7 & 6 & $4(66 \%)$ \\
\hline Gleason's grade $<7$ & 6 & $2(33 \%)$ \\
\hline \multicolumn{2}{|c|}{ Table 3 } \\
\hline
\end{tabular}

\begin{tabular}{|c|c|c|}
\hline \multirow{2}{*}{$\begin{array}{c}\text { Test } \\
\text { (MR Spectroscopy) }\end{array}$} & Disease (Carcinoma Prostate) \\
\cline { 2 - 3 } & Present & Absent \\
\hline Present & 16 & 2 \\
\hline Absent & 6 & 6 \\
\hline \multicolumn{3}{|c|}{ Table 4 } \\
\hline
\end{tabular}

\section{Total No. of Patients were 30}

- Sensitivity is $72.72 \%$

- $\quad$ Specificity is $75 \%$

- Positive predictive value is $88.88 \%$

- $\quad$ Negative predictive value is $50 \%$ 


\section{PSA-Related Data}

Age, gland volume and PSA-related data associated with the cancer-yield and non-cancer-yield groups are compared in Table 1 . The difference in the PSA values between the two groups was significantly higher in malignant group, TRUSguided gland volume was not significant between two groups.

\section{Follow-Up Status}

Immediately, after the TRUS-guided biopsy procedure, only one patient experienced anal pain and bleeding during defecation $(3.3 \% ; 1 / 30)$. None had haematuria or urinary retention. One patient (3.3\%) experienced systemic infection and required intravenous antibiotics treatment. Patients with negative biopsy is on regular follow-up.

\section{DISCUSSION}

MR spectroscopy is a promising development in the radiological evaluation of possible prostate malignancy. The MR spectroscopic evaluation is mainly based on the choline peak elevation and choline-creatinine ratios.

\section{Choline/ Creatine to Citrate Ratios}

- 0.5: suspicious.

- 0.8 : very suspicious.

- 2.5: abnormal.

Additionally, the peak heights of citrate and choline can be compared visually. The question arises as to whether or not it is possible to use spectroscopy as a method to improve tumour diagnosis during the MRI exam.

First, the validity of the method was verified. MRI spectroscopy verified the middle values of the cho $+\mathrm{cr} / \mathrm{cit}$ ratio of the spectrum for healthy and tumourous areas of the prostate revealing a significant difference in these values.

In healthy tissue values of $0.35( \pm 0.10)$ were obtained, while in cancerous tissue a value of $2.70( \pm 0.20)$ was obtained and was somewhat elevated compared to other studies.

In our study, MRSI detected malignancy was $100 \%$ for high-grade tumours, $66 \%$ for intermediate grade tumours and $33 \%$ for low-grade tumours. PSA values were also elevated in proportion to elevation of choline - citrate ratio. Choline - citrate ratio was also elevated in 4 patients with negative biopsy.

Tissues defined by values Goeb et al: MRI Spectroscopy in Prostate Cancer greater than $0.22+3$ standard deviations were highly suspected as tumour. Mueller-Lisse et al(4) concluded that $0.24 \pm 0.13$ were values for healthy tissue and those tissues with 3 standard deviations were considered tumourous.

Scheidler et al(5) reported results somewhat less accurate and stated that tissue with a ratio less than 0.75 was healthy and tissue greater than 0.75 was tumourous. Nevertheless, these studies only considered high quality voxels for the spectroscopy, which would explain the higher values obtained in our examination (Spectroscopy was not always optimal). In particular, elderly patients could not always be positioned comfortably in order to minimise the motion effect artefact. Another criterion for the quality of the measurement was the positioning of the presets in the periprostatic space in order to mask disturbing fat signals (Outer volume suppression). Depending on the form and size of the prostate, complete suppression could not always be guaranteed. Gradient shimming could not compensate for all of the inhomogeneities inherent to the magnet field.

As a result, the bandwidth of the spectrum caused a loss in the accuracy. Another limitation was the voxel selection. In the above-mentioned studies,(6) only the voxels from the peripheral zone were selected. In this location $60 \%$ to $75 \%$ of the prostate carcinomas are generally found, while $10 \%$ to $15 \%$ of tumours are located in the transitional zone.(1) Kaji et al confirmed with healthy volunteers a normal cho $+\mathrm{cr} / \mathrm{cit}$ ratio range from $0.58 \pm 0.38$ for the peripheral zone and from $0.72 \pm 0.51$ for the transitional zone of the gland. $(7)$

Since a significant difference could be proved regarding the metabolic ratio of healthy and tumourous tissue, it appears that MRI spectroscopy was an appropriate tool for the discovery of primary tumours in the prostate. Compared to a standard T2 weighted examination, a combination of MRI spectroscopy and the pathology clearly improved the accuracy of the interpretation in 6 out of 12 cases (50\%). Scheidler et al(5) also increased the MRSI sensitivity and specificity for tumour identification by combining these techniques as opposed to using a single imaging technique. Kurhanewicz et al increased the target accuracy with the confirmation of the tumour volume and location using spectroscopy.(5)

Differentiation in the central zone of the BHP of a prostate carcinoma can become meaningful with spectroscopy, as the tumour can easily be interpreted as a BHP if only the single imaging technique is used.(8) Therefore, the spectroscopy study can help to more accurately make the differentiation between tumour and BHP. MR spectroscopy can also provide helpful diagnostic information in defining the location of tumours in patients with excessive bleeding following biopsy procedures.(9)

Despite the fact that the imaging was improved, there were false positive results regarding the overestimation of tumour size. Spectroscopy should not be used alone to determine tumour size, since false positive results can also be obtained due to the inaccuracy of the measurement or a large hyperplastic nodule in the inner gland. (Kurhanewicz et al,(10) small overlaps of the cho $+\mathrm{cr} / \mathrm{cit}$ - ratio of normal tissue of the peripheral zone and $\mathrm{BHP}$ ).

The metabolic changes observed by MRSI take advantage of the well-documented unique metabolism of healthy prostate epithelial cells, which have the specialised function of synthesizing and secreting large amounts of citrate which is dramatically reduced or lost in prostate cancer.(11-15)

The decrease in citrate with prostate cancer is due both to changes in cellular function(15) and changes in the organisation of the tissue, resulting in a loss of its characteristic ductal morphology.(16,17)

The loss of citrate in prostate cancer is intimately linked with changes in zinc levels that are extraordinarily high in healthy prostate epithelial cells.(17,22) In healthy prostatic epithelial cells the presence of high levels of zinc inhibit the enzyme aconitase, thereby preventing the oxidation of citrate in the Krebs' cycle. $(13,18)$

Costello and Franklin have shown that these elevated levels of zinc are primarily due to increased expression of ZIP-type plasma membrane $\mathrm{Zn}$ uptake transporters (primarily Human ZIP-1).(14) 
Human ZIP-1 is reduced and zinc levels are dramatically reduced in prostate cancer and the malignant epithelial cells and there exists evidence that the loss of the capability to retain high levels of zinc is an important factor in the development and progression of prostate cancer.(13,18) It is also believed that the transformation of prostate epithelial cells to citrate-oxidizing cells, which increases energy production capability is essential to the process of malignancy and metastasis.(12)

The elevation of choline-containing metabolites [phosphocholine (PC), glycerophosphocholine (GPC), free choline (Cho)] and the over and under-expression of key enzymes in phospholipid membrane synthesis and degradation, specifically choline kinase and a number of the phospholipases have been associated with the presence, progression and therapeutic response of a variety of human cancers including prostate.(19-21)

The addition of MR spectroscopic data to the conventional MRI has improved detection of clinically significant prostate cancer and improves sensitivity from 68 to 78 percent.

Addition of an MRSI estimate improved the accuracy in the diagnosis of extracapsular extension of prostate cancer, significantly improved the prediction of indolent prostate cancer using a surgical definition of indolent disease (no SVI, ECE and $<0.5 \mathrm{~cm}^{3}$ of cancer with no pattern 4 or 5 cancer) as the standard of reference.

Metabolic Atrophy: The presence of $\geq 3$ voxels having a choline/ creatine $\geq 1.5$ in a hemi-prostate is needed for the diagnosis of local cancer recurrence.

\section{False Positive}

Prostatitis and Stromal BPH.

\section{False Negative}

Low-grade tumour, anterior/ central gland tumours.

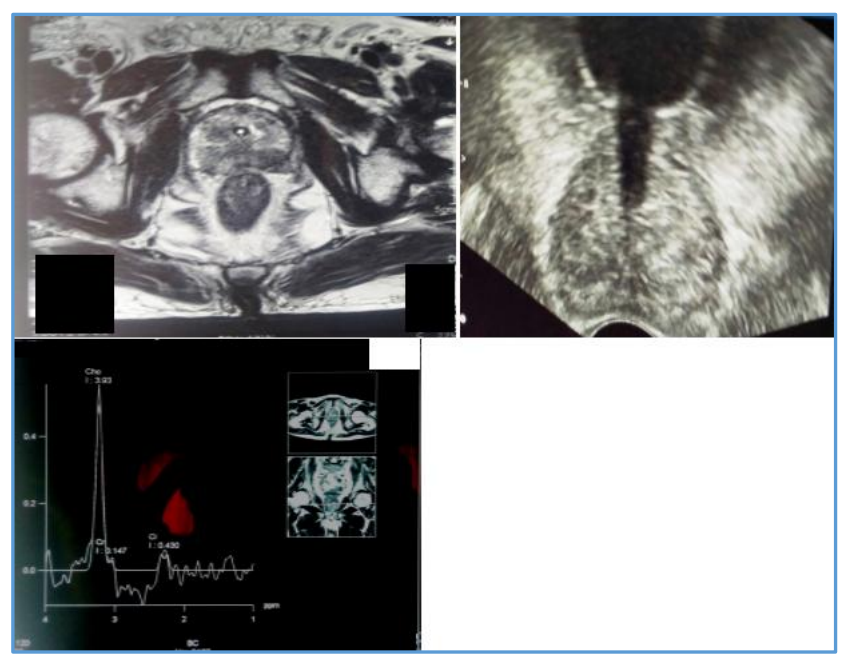

Images showing: a) MRI showing Suspicious Lesion in RT Lobe of Prostate, b) Corresponding Hypoechoic Lesion in TRUS, c) MRSI showing Choline-Citrate Peak Elevation

\section{CONCLUSION}

In our study, MRSI had sensitivity of around $72 \%$ and specificity of $75 \%$ with considering MRI-TRUS fusion biopsy as the standard of care for diagnosis of carcinoma prostate. The diagnostic ability of MRSI alone is lower compared with
MP-MRI, particularly for low-grade tumours. It is also falsely elevated for other benign conditions like prostatitis. Spectroscopy in combination with MRI appears to be an appropriate method for determining the location and diagnosis of prostate carcinoma. Based on our examinations, we do not recommend the use of spectroscopy alone as the primary tool for the recognition of prostate carcinomas.

\section{REFERENCES}

[1] Muller-Lisse UL, Hofstetter A. Urological diagnosis of prostate carcinoma. Radiologe 2003;43(6):432-40.

[2] Heuck A, Scheidler J, Sommer B, et al. MR imaging of prostate cancer. Radiologe 2003;43(6):464-73.

[3] Padhani AR, MacVicar AD, Gapinski CJ, et al. Effects of androgen deprivation on prostatic morphology and vascular permeability evaluated with MR imaging. Radiology 2001;218(2):365-74.

[4] Mueller-Lisse UG, Swanson MG, Vigneron DB, et al. Time-dependent effects of hormone-deprivation therapy on prostate metabolism as detected by combined magnetic resonance imaging and 3D magnetic resonance spectroscopic imaging. Magn Reson Med 2001;46(1):49-57.

[5] Scheidler J, Hricak H, Vigneron DB, et al. Prostate cancer: localization with three-dimensional proton MR spectroscopic imaging-clinicopathologic study. Radiology 1999;213(2):473-80.

[6] Jung JA, Coakley FV, Vigneron DB, et al. Prostate depiction at endorectal MR spectroscopic imaging: investigation of a standardized evaluation system. Radiology 2004;233(3):701-8.

[7] Kaji Y, Wada A, Imaoka I, et al. Proton twodimensional chemical shift imaging for evaluation of prostate cancer: external surface coil vs. endorectal surface coil. J Magn Reson Imaging 2002;16(6):697706.

[8] Stanka M, Eltze E, Semjonow A, et al. Spectroscopic imaging (1H-2D-CSI) of the prostate: sequence optimization and correlation with histopathological results. Rofo 2000;172(7):623-9.

[9] Kaji Y, Kurhanewicz J, Hricak H, et al. Localizing prostate cancer in the presence of postbiopsy changes on MR images: role of proton MR spectroscopic imaging. Radiology 1998;206(3):785-90.

[10] Kurhanewicz J, Vigneron DB, Hricak H, et al. Threedimensional H-1 MR spectroscopic imaging of the in situ human prostate with high (0.24-0.7-cm3) spatial resolution. Radiology 1996;198(3):795-805.

[11] Costello LC, Franklin RB. Concepts of citrate production and secretion by prostate. 1. Metabolic relationships. Prostate 1991;18(1):25-46.

[12] Costello LC, Franklin RB. Bioenergetic theory of prostate malignancy. Prostate 1994;25(3):162-6.

[13] Costello LC, Franklin RB. Novel role of zinc in the regulation of prostate citrate metabolism and its implications in prostate cancer. Prostate 1998;35(4):285-96.

[14] Franklin RB, Ma J, Zou J, et al. Human ZIP1 is a major zinc uptake transporter for the accumulation of zinc in prostate cells. J Inorg Biochem 2003;96(2-3):435-42. 
[15] Costello LC, Franklin RB. Concepts of citrate production and secretion by prostate: 2. Hormonal relationships in normal and neoplastic prostate. Prostate 1991;19(3):181-205.

[16] Kahn T, Burrig K, Schmitz-Drager B, et al. Prostatic carcinoma and benign prostatic hyperplasia: MR imaging with histopathologic correlation. Radiology 1989;173(3):847-51.

[17] Schiebler ML, Tomaszewski JE, Bezzi M, et al. Prostatic carcinoma and benign prostatic hyperplasia: correlation of high-resolution MR and histopathologic findings. Radiology 1989;172(1):131-7.

[18] Liang JY, Liu YY, Zou J, et al. Inhibitory effect of zinc on human prostatic carcinoma cell growth. Prostate 1999;40(3):200-7.
[19] Swanson MG, Vigneron DB, Tabatabai ZL, et al. Proton HR-MAS spectroscopy and quantitative pathologic analysis of MRI/3D-MRSI-targeted postsurgical prostate tissues. Magn Reson Med 2003;50(5):944-54.

[20] Swanson MG, Zektzer AS, Tabatabai ZL, et al. Quantitative analysis of prostate metabolites using $1 \mathrm{H}$ HR-MAS spectroscopy. Magn Reson Med 2006;55(6):1257-64.

[21] Ackerstaff E, Pflug BR, Nelson JB, et al. Detection of increased choline compounds with proton nuclear magnetic resonance spectroscopy subsequent to malignant transformation of human prostatic epithelial cells. Cancer Res 2001;61(9):3599-603. 